\title{
Studies on protein degradation and carbohydrate fermentation of the grasses from the winter pastures in northwest China
}

\author{
J-Q Wang \\ Animal Science Institute, Chinese Academy of Agricultural Sciences Beiiing 100094, China
}

In northwest China, during the cold season grazing animals maintain life on the grasses left on the pasture after summer grazing as it is difficult to make hay in the warm season because of the low productivity of the grassland. But there is little information about the nutritive value of the winter grasses. The purpose of this research was to investigate the protein and carbohydrate degradation of the winter grasses in the rumen using nylon bag technique.

Six sheep with permanent rumen cannulae were used and fed at maintenance requirement (NRC, 1985). One representative sample of the winter mix grass cover (Elymus sp., «Daharia wildryegrass"; Achnatherum sp., "Lovely achnatherum» and Poa pratensis, "Kentucky blue grass") was collected in November, sampled and ground through $1 \mathrm{~mm}$ screen for nylon bag determination. The nylon bag technique was carried out according to the procedure of Stern and Satter (1984, J Anim Sci, 58, 714). The degradation parameters were calculated using equations:

$d p=a+b\left(1-e^{-c l}\right)$ and $p=a+b c /(c+k)$ in which "a» is the rapid degradable fraction, "b» is the potential degradable fraction, " $c$ " is the degradation rate constant, "k" is the outflow rate constant, " $p$ " is the effective degradability.

The composition of the grass was : organic matter (OM) 93.9, crude protein (CP) 3.8, neutral detergent fibre (NDF) 67.5 and acid detergent fibre (ADF) $42.4 \%$ respectively. For the optimum microbial synthesis and fibre digestion in the rumen, fermentable organic matter (FOM) and rumen degradable protein (RDP) have to keep synchronized. According to NRC (1990), the optimum proportion between FOM and RDP is $161 \mathrm{~g}$ RDP per $\mathrm{kg}$ FOM. Because of the low crude protein content in the grasses, RDP/FOM $(\mathrm{g} / \mathrm{kg})$ was much lower than the optimum level at any time in the rumen $(p<0.05)$.

In conclusion, lack of RDP compared to FOM in the winter grasses is the main limiting nutritive factor for rumen microbial synthesis and animal growth during cold season in northwest China pastures.

Chemical composition and degradation of the grasses on winter pastures

\begin{tabular}{lrrrrrrrrrrc} 
Items & $\% \mathrm{DM}$ & \multicolumn{1}{c}{ Degradability \% } \\
& & $6 \mathrm{~h}$ & $12 \mathrm{~h}$ & $24 \mathrm{~h}$ & $36 \mathrm{~h}$ & $48 \mathrm{~h}$ & $72 \mathrm{~h}$ & $\mathrm{a}$ & $\mathrm{c}$ & $\mathrm{p}$ \\
OM & 93.9 & 25.9 & 35.2 & 48.6 & 56.4 & 65.8 & 73.5 & 16 & 0.026 & 47.3 \\
CP & 3.8 & 52.5 & 55.3 & 60.5 & 63.3 & 65.5 & 71.9 & 50 & 0.013 & 35.9 \\
NDF & 67.5 & 10.3 & 19.5 & 35.7 & 39.6 & 57.9 & 68.0 & 2 & 0.017 & 60.8 \\
ADF & 42.4 & 4.5 & 20.0 & 33.4 & 41.9 & 55.4 & 65.5 & 0 & 0.025 & 33.4 \\
RDP/FOM (g/kg) & 82.3 & 63.5 & 50.4 & 45.5 & 40.3 & 39.6 & - & - & - & - \\
k=0.0300 & & & & & & & & & &
\end{tabular}

